Check for updates

Cite this: Mater. Chem. Front. 2020, 4, 2054

Received 25th April 2020,

Accepted 28th May 2020

DOI: $10.1039 / \mathrm{d0qm} 00265 \mathrm{~h}$

rsc.li/frontiers-materials

\title{
Spray-coated PEDOT:OTf films: thermoelectric properties and integration into a printed thermoelectric generator $\dagger$
}

\author{
Etienne Yvenou, ${ }^{a}$ Martina Sandroni, ${ }^{\text {ab }}$ Alexandre Carella, ${ }^{\text {a }}$ Magatte N. Gueye, ${ }^{\text {ab }}$ \\ Jérôme Faure-Vincent, ${ }^{b}$ Stéphanie Pouget, $\mathbb{D D}^{\mathrm{c}}$ Renaud Demadrille $\mathbb{D}^{\mathrm{b}}$ and \\ Jean-Pierre Simonato (iD *ad
}

\begin{abstract}
Organic conducting polymers are promising materials for thermoelectric applications due to their high electrical conductivity and intrinsic low thermal conductivity. Among them, poly(3,4-ethylenedioxythiophene) (PEDOT) has a positive Seebeck coefficient (p-type) and is commercially available. It has therefore gained a lot of attention in the field. However, it remains challenging to process a large amount of organic thermocouples to produce an efficient thermoelectric generator (TEG). In addition, finding a way to use bidimensional (2D) printed thermocouples in a tridimensional (3D) TEG structure is not straightforward. In this article, we propose the use of ultrasonic spray-coating as a straightforward large-scale printing technique to prepare highly conducting and in situ polymerized PEDOT:OTf. The spray-coated material can reach an electrical conductivity as high as $2215 \pm 665 \mathrm{~S} \mathrm{~cm}^{-1}$ at $132 \pm 10 \mathrm{~nm}$ film thickness. We studied the influence of several parameters, such as co-solvent addition, thickness control and rinsing procedure on the conduction properties. GIWAXS and low temperature electrical conductivity measurements on films of different thicknesses allowed us to elucidate the structures of the as-prepared materials and the charge transport mechanisms. Finally, a fully printed and rolled TEG containing 156 thermocouples was prepared as a proof of concept, generating a power output of $1 \mu \mathrm{W}$ with a $48^{\circ} \mathrm{C}$ thermal gradient.
\end{abstract}

\section{Introduction}

In 2016 , it was estimated that around $72 \%$ of the energy produced in the world was lost as heat after conversion. Most of the energy (63\%) is lost in relatively cold sources (below $100{ }^{\circ} \mathrm{C}$ ) and is qualified as low grade waste heat. ${ }^{1}$ Thermoelectric generators (TEG) are constituted by segments of n-type and p-type semiconductors connected thermally in parallel and electrically in series. They convert a temperature gradient into electrical energy. ${ }^{2,3}$ Therefore, these devices can harvest heat losses and convert them directly into electricity. The main advantages of TEG are the lack of any moving parts, their reliability and low maintenance. The performances of TEG are defined by the dimensionless figure of merit

$$
Z \bar{T}=\frac{\alpha^{2} \sigma}{\lambda} \bar{T}
$$

\footnotetext{
${ }^{a}$ Univ. Grenoble Alpes, CEA, LITEN, DTNM, F-38000 Grenoble, France. E-mail: alexandre.carella@cea.fr, jean-pierre.simonato@cea.fr

${ }^{b}$ Univ. Grenoble Alpes, CEA, CNRS, IRIG, SYMMES, F-3800o Grenoble, France

${ }^{c}$ Univ. Grenoble Alpes, CEA, CNRS, IRIG, MEM, F-38000 Grenoble, France

${ }^{d}$ Department of Chemistry, Duke University, Durham, NC 27708, USA

$\dagger$ Electronic supplementary information (ESI) available. See DOI: 10.1039/d0qm00265h
}

where $\sigma$ is electrical conductivity (in $\mathrm{S} \mathrm{m}^{-1}$ ), $\alpha$ is the Seebeck coefficient $\left(\alpha=-\frac{\Delta V}{\Delta T}\right.$, in $\left.\mathrm{V} \mathrm{K}^{-1}\right), \lambda$ is thermal conductivity (in $\mathrm{W} \mathrm{m}^{-1} \mathrm{~K}^{-1}$ ) and $\bar{T}$ is the average temperature (in $\mathrm{K}$ ). Efficient thermoelectric materials have therefore high $\sigma$ and $\alpha$, and low $\lambda$, a combination of properties that is often referred to as "electron crystal, phonon glass". The product $\alpha^{2} \sigma$ is called power factor ( $\mathrm{PF}=\alpha^{2} \sigma$ in $\mathrm{W} \mathrm{m} \mathrm{m}^{-1} \mathrm{~K}^{-2}$ ) and is often used to characterize the TE performances. ${ }^{4,5}$ Common thermoelectric inorganic materials like $\mathrm{Bi}_{2} \mathrm{Te}_{3}$ alloys show excellent TE efficiency, with $Z \bar{T}$ typically higher than 1.3 at $373 \mathrm{~K}^{6,7}$ However, their application on a large scale is not convenient due to toxicity and scarcity of the constituting elements, and their expensive fabrication process. Consequently, organic thermoelectric materials based on conductive polymers (CPs $)^{5,8-12}$ or small molecules ${ }^{13,14}$ are gaining momentum as possible alternative materials, thanks to a variety of structures and adjustable properties as well as their easy and low-cost fabrication. Moreover, organic materials can possibly be deposited on various surfaces using printing techniques like screenprinting, ink-jet, flexography and spray-coating. ${ }^{15-17}$ Similarly to inorganic thermoelectric materials, conductive polymers 
should behave as "electronic crystals and phonon glasses" to efficiently convert heat into electricity. In other words, the goal is to design a solid material that is a poor conductor of heat, like a glass, while keeping the good electrical properties associated with crystals. ${ }^{18}$ In the last two decades, massive research efforts were focused on the development of conducting polymers showing high electrical conductivity. Nowadays, some p-type materials exhibit excellent electrical performances with conductivities above $1000 \mathrm{~S} \mathrm{~cm}^{-1}$. Amongst these materials, polyaniline (PANI) and poly(ethylenedioxythiophene):polystyrenesulfonate (PEDOT) and their hybrid composites were thoroughly studied for use in thermoelectric devices. ${ }^{19-23}$

In the meantime, less efforts were done on n-type polymers and their lower electrical conductivities still refrain the development of OTEGs capable to compete with inorganic thermoelectric generators. $^{24}$

Since the thermal conductivities are intrinsically low for organic materials, the critical parameter to control and optimize to attain high-performance thermoelectric devices is the power factor, via concomitant increase of both the electrical conductivity and the Seebeck coefficient.

Among CPs, poly(3,4-ethylenedioxythiophene) (PEDOT) arouses great interest in the scientific community because of its high electrical conductivity (up to several thousand $\mathrm{S} \mathrm{cm}^{-1}$ ) and a relatively high environmental stability. ${ }^{25-30}$ Furthermore, in presence of the hydrophilic counter-anion polystyrenesulfonate (PSS), PEDOT can be dispersed in water (PEDOT:PSS), which greatly facilitates its handling. Such solutions of PEDOT:PSS are commercially available. Oxidative polymerization of EDOT was reported for the first time at the end of the 1980's, ${ }^{31}$ and since then it has been achieved using a variety of ferric salts in presence of the tri-block-copolymer PEGPPG-PEG. ${ }^{32-34}$ The role of this copolymer is manifold. It contains a small amount of water needed for efficient EDOT deprotonation, and at the same time it prevents the iron salt crystallization in presence of water, and moderates the polymerization rate. We reported in 2015 that the use of $\mathrm{Fe}(\mathrm{OTf})_{3}$ as the oxidizing agent resulted in a dramatic enhancement of PEDOT conductivity in particular due to the increase of the mean size of crystalline domains with respect to PEDOS:PSS. ${ }^{35,36}$ Here, we report the synthesis of spray-coated films of in situ polymerized PEDOT:OTf. High electrical conductivity is achieved, $2215 \pm 665 \mathrm{~S} \mathrm{~cm}^{-1}$ in average with the best sample measured at $2750 \mathrm{~S} \mathrm{~cm}^{-1}$. Spray coating is a powerful technique, which allows easy printing of highly conductive films with thicknesses ranging from hundreds of $\mathrm{nm}$ to several $\mu \mathrm{m}$, on relatively wide and potentially rough areas. Large thickness is found to be crucial in order to lower the internal resistance $\left(R_{\mathrm{i}}\right)$ for future application in thermoelectric devices. As a proof of concept, we present a TEG device composed of 156 PEDOT:OTf and silver thermocouples.

\section{Experimental methods}

\section{Chemicals and materials}

Copolymer poly(ethylene glycol)-block-poly(propylene glycol)block-poly(ethylene glycol) (PEG-PPG-PEG) with a $M_{\mathrm{w}}$ of
$5800 \mathrm{~g} \mathrm{~mol}^{-1}$, methanol, absolute ethanol, isopropanol (IPA, $\geq 99.8 \%$ ), $N$-methyl-2-pyrrolidone (NMP, $\geq 99.0 \%$ ), iron(III) trifluoromethanesulfonate $\left(\mathrm{Fe}(\mathrm{OTf})_{3}, 90 \%\right)$ and 3,4-ethylenedioxythiophene (EDOT, 97\%) were purchased from Sigma Aldrich and used as received without further purification. Coatings were prepared on microscope soda lime glass slides from VWR for the study of the thermoelectric properties. Printed TEGs were made on $25 \mu \mathrm{m}$ thick polyimide foil (100 HN Kapton $\left.{ }^{\circledR}\right)$ from DUPONT.

\section{Oxidizing solution preparation}

The PEDOT:OTf films were prepared by in situ oxidative polymerization of the EDOT monomer, using $\mathrm{Fe}(\mathrm{OTf})_{3}$ as the oxidant, in presence of $10 \mathrm{wt} \%$ PEG-PPG-PEG. NMP was used as a co-solvent in a concentration range from 0 to $7 \mathrm{wt} \%$. Solution_EtOH was prepared by mixing $10 \mathrm{wt} \%$ PEG-PPG-PEG and $90 \mathrm{wt} \%$ ethanol. Solution_NMP was prepared by mixing $10 \mathrm{wt} \%$ PEG-PPG-PEG and $90 \mathrm{wt} \%$ NMP. For the synthesis of PEDOT:OTf, solution_EtOH was added to a determined amount of solution_NMP, in order to obtain the desired NMP percentage. For example, in order to obtain $x$ wt\% of NMP in the final solution, $m_{\mathrm{NMP}} \times(90-x) / x$ of solution_EtOH was added to a weighted amount $m_{\mathrm{NMP}}$ of solution_NMP. Finally, Fe(OTf $)_{3}$ (63 $\mathrm{mg} \mathrm{mL}^{-1}, 125 \mathrm{mM}$ ) was dissolved in this solution. The obtained oxidative solution was sonicated for $2 \mathrm{~h}$ before being used. Just before spray-coating, EDOT (9.5 $\left.\mu \mathrm{L} \mathrm{mL}{ }^{-1}, 89 \mathrm{mM}\right)$ was added with a micro-syringe and the reactive mixture was manually shaken for $40 \mathrm{~s}$. Once the monomer and the oxidant are mixed together, the solution has to be used in the following two hours in order to avoid polymerization starting before the spray coating process.

\section{Film preparation}

Spray coating was performed with an ExactaCoat Benchtop Ultrasonic Spraying System from Sono-Tek Corp. A $48 \mathrm{kHz}$ ultrasonic nozzle nebulized the reactive solution into micrometer sized drops shaped by compressed air. The distance between the nozzle and the substrates $\left(25 \times 25 \mathrm{~mm}^{2}\right)$ was fixed at $8 \mathrm{~cm}$. The substrates were cleaned with absolute ethanol and cleanroom nonwoven polyester fabrics prior to spray coating. The chuck plate was heated at $70{ }^{\circ} \mathrm{C}$ during spray coating. A layer of PEDOT:OTf film consists of displacements along the $x$ then on the $y$ axis successively. Each displacement is separated by an offset of $4 \mathrm{~mm}$ in the perpendicular direction. Regardless the size of the nebulized surface, the films were annealed for $10 \mathrm{~min}$ at $70{ }^{\circ} \mathrm{C}$ immediately after the spray-coating deposition step in order to achieve complete polymerization. After annealing, the films were dipped in absolute ethanol $(2 \times 2 \mathrm{~min})$ to remove solvent in excess, PEG-PPG-PEG and unpolymerized material. They were then dried for $10 \mathrm{~min}$ at $70{ }^{\circ} \mathrm{C}$. Homogeneous PEDOT:OTf films were produced with at least two overlaid depositions. The whole process is schematized in Fig. S1 (ESI $\dagger$ ).

\section{Characterization}

Electrical conductivity at room temperature was calculated from the sheet resistance (mean value of five measurements 
on different areas of the film with a 4 probe system Loresta-EP MCP-T360) and the thickness, measured by atomic force microscopy (AFM) in Tapping Mode with an Innova model from Bruker. Seebeck coefficient was measured on $1 \times 2 \mathrm{~cm}^{2}$ rectangular samples under helium atmosphere at $-0.05 \mathrm{MPa}$ relative pressure on a ZEM-3 system from Ulvac. Electrical contacts with diameter between 1 and $3 \mathrm{~mm}$ were brush painted with a silver ink (L-200N from Ferro) in order to have an ohmic contact between type- $\mathrm{R}$ thermocouples. The distance between contacts was limited to $8 \mathrm{~mm}$ maximum due to the ZEM-3 setup. Even if the distance was relatively short, no significant overestimation of the Seebeck coefficient was observed with respect to literature values, as reported by Reenen. ${ }^{37}$ UV-Vis-NIR specular spectra were recorded on a Cary 5000 from Varian between 350 and $2000 \mathrm{~nm}$. Fourier Transform IR (FTIR) spectra were recorded on a Vertex 70 from Bruker by attenuated total reflectance (ATR) method using a germanium crystal (cutoff at $575 \mathrm{~cm}^{-1}$ and $\mathrm{He}-\mathrm{Ne}$ laser excitation at $632.8 \mathrm{~nm}$ ). Grazing-incidence wideangle X-ray scattering (GIWAXS) were performed on a Rigaku Smartlab diffractometer equipped with a copper rotating anode; the two degrees of freedom of the detector allow outof-plane and in-plane measurements. The value of the incident angle, of the order of a few tenths of a degree, was optimized for each sample. Finally, electronic charge transport mechanisms in PEDOT:OTf films were determined by measuring electrical conductivities down to $3 \mathrm{~K}$ with a helium flow cryostat $\mathrm{CF}$ $1200 \mathrm{D}$ from Oxford Instruments.

\section{Silver spray coating}

The silver strips used for connecting the PEDOT:OTf elements in the TEG were deposited using a manual airbrush (Aztek A4709), and 5069 silver ink from Dupont. After the deposition of the ink (3 layers), the silver strips were annealed at $130{ }^{\circ} \mathrm{C}$ for $30 \mathrm{~min}$ to optimize both internal resistance and Seebeck coefficient. After thermal annealing, the silver ink had an internal sheet resistance of $0.34 \pm 0.09 \Omega \square^{-1}$ and a Seebeck coefficient of $2.3 \mu \mathrm{V} \mathrm{K}^{-1}$.

\section{Results and discussion}

\section{Impact of the formulation}

PEDOT:OTf films obtained by spin-coating on glass an oxidative solution containing 3,4-ethylenedioxythiophene (EDOT), Fe(OTf) as oxidant, and PEG-PPG-PEG usually exhibit conductivities in the 1000-1200 $\mathrm{S} \mathrm{cm}^{-1}$ range. This can be improved up to $3600 \mathrm{~S} \mathrm{~cm}^{-1}$ by adding a co-solvent. ${ }^{35,36}$ However, spin-coating deposition provides quite thin films (typically with thicknesses below $100 \mathrm{~nm}$ ), and is not well adapted to cover large surfaces. Therefore, we decided to optimize the polymerization conditions using spray-coating, which is an easy-to-handle deposition technique, certainly more appropriate to produce thick and large area films as required for the production of TEG devices. We first improved the stability and the lifetime of the oxidative solution, in particular through an optimization of the $\mathrm{Fe}(\mathrm{OTf})_{3}$ concentration. The influence of the concentration of the iron salt on the electrical conductivity is shown in Fig. S2 (ESI $\dagger$ ) for samples having thicknesses between 540 and $940 \mathrm{~nm}$. The experimental details are given in Table S1 (ESI $\dagger$ ). The optimum concentration was found to be $63 \mathrm{mg} \mathrm{mL}$ (0.125 mM, 10 wt\% PEG-PPG-PEG) where PEDOT:OTf films reached an average electrical conductivity of $717 \pm 110 \mathrm{~S} \mathrm{~cm}^{-1}$.

Reported results in the literature highlight that the electrical conductivity of in situ polymerized PEDOT can be increased by adding coordinating molecules or co-solvents to the oxidative solution like imidazole, ${ }^{38}$ pyridine $^{39}$ or NMP. ${ }^{36}$ We demonstrated in a previous work that the addition of NMP as a co-solvent results in an increase of the electrical conductivity from around 1000 up to $3600 \mathrm{~S} \mathrm{~cm}^{-1}$ for spin-coated PEDOT:OTf films. $^{36}$ This was demonstrated to slower polymerization kinetics, allowing a better organization of the polymer chains, which leads to an enhanced crystallinity in the film. It seemed thus of interest to validate whether the same result would be obtained for spray-coated PEDOT:OTf films.

Fig. 1 shows the influence of the amount of NMP on the film thickness, the electrical conductivity, the Seebeck coefficient and the power factor for spray coated PEDOT:OTf films (2 layers of polymer in each case). The thickness decreased with increasing amount of NMP from $800 \mathrm{~nm}$ without NMP up to $132 \mathrm{~nm}$ for $5 \mathrm{wt} \%$ NMP solutions. From 0 to $5 \mathrm{wt} \%$ of NMP, the electrical conductivity increases with the rising amount of co-solvent. The best electrical conductivity is reached when adding $5 \mathrm{wt} \%$ of NMP into the oxidative solution at $2278 \pm 620 \mathrm{~S} \mathrm{~cm}^{-1}$. At higher NMP concentration (e.g. $6 \mathrm{wt} \%$ ), the morphology of the film appears no longer homogenous, leading to a drop of the electrical conductivity (Fig. S3, ESI $\dagger$ ).

The addition of NMP does not alter significantly the Seebeck coefficient of PEDOT:OTf films which sits in the $15-20 \mu \mathrm{V} \mathrm{K}^{-1}$ range, with an average value of $18.0 \mu \mathrm{V} \mathrm{K} \mathrm{K}^{-1}$. These data are consistent with most literature reports. ${ }^{24,40}$ The $\mathrm{PF}$ values follow the electrical conductivity trend, with a maximum value of $105 \mu \mathrm{W} \mathrm{m} \mathrm{m}^{-1} \mathrm{~K}^{-2}$ for $5 \mathrm{wt} \%$ of NMP. This power factor is comparable to the one of thin PEDOT:PSS films after posttreatment. ${ }^{41}$

Process parameters. One of the main hurdles in the fabrication of organic TEG is to obtain a low internal resistance in order to minimize Joule losses. To that end, we increased the thickness of PEDOT:OTf films from few tens of nanometres to the micrometre scale by increasing the number of deposited layers. Two processing methods were compared, namely stacked layers (SL) and continuous layers (CL). In the SL case, the films are annealed every two coated layers, then rinsed with ethanol and finally the whole process is repeated until the desired number of layers is reached. On the other hand, for CL, the films are annealed and rinsed in ethanol only once the total desired number of layers is printed. The effect of the two treatments is shown in Fig. 2a, where the thickness evolution is reported as a function of the number of layers. In the case of SL, the thickness per layer remains almost constant between 145 and $185 \mathrm{~nm}$ per layer, while for continuous layers it rises from 160 to $350 \mathrm{~nm}$ per layer. This can be explained by pointing out the importance of the rinsing step, which is described in more 

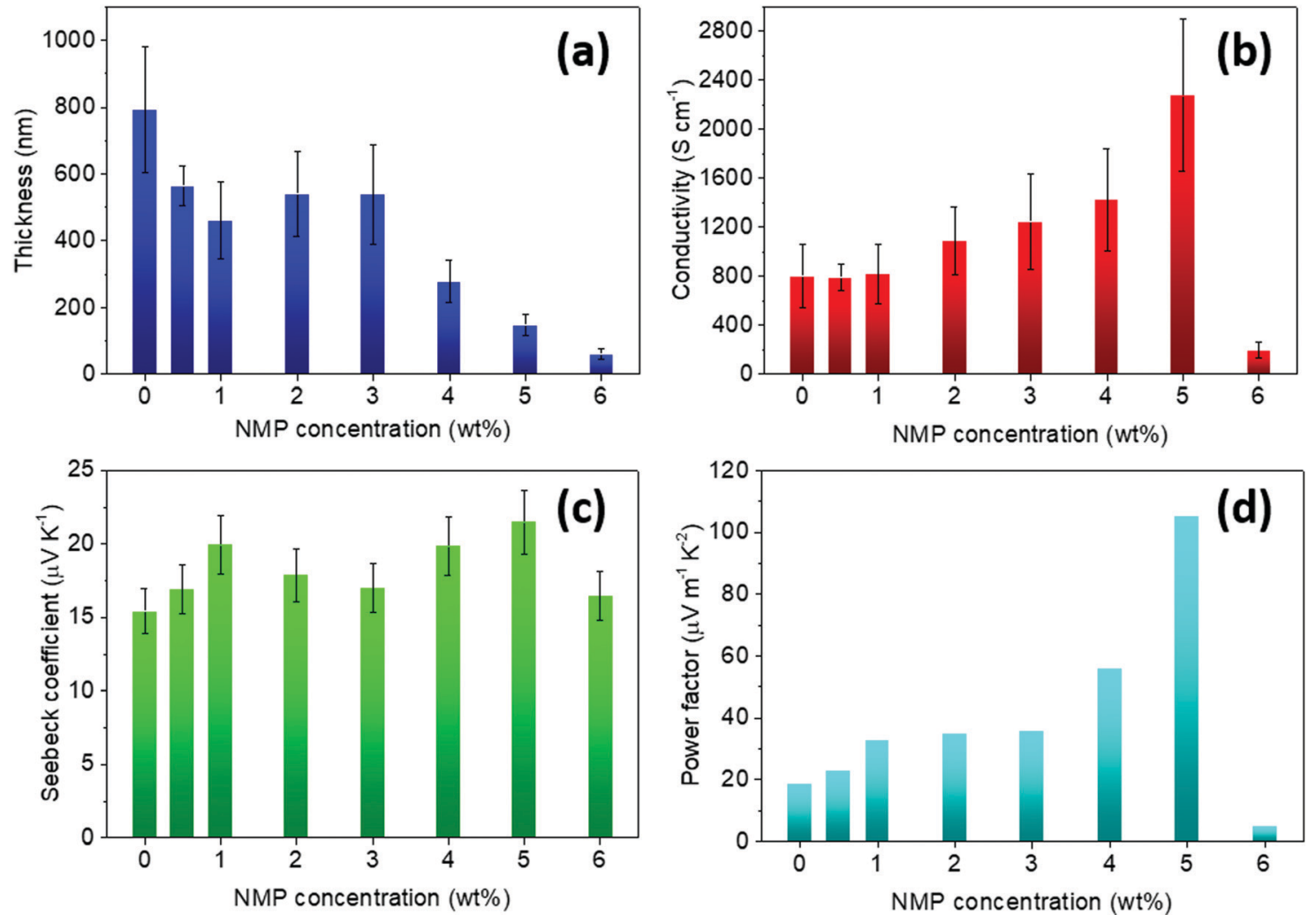

Fig. 1 Evolution of (a) the thickness, (b) the electrical conductivity, (c) the Seebeck coefficient and (d) the calculated power factor for PEDOT:OTf films with increasing amount of NMP in the oxidizing solution. The numerical values for all the parameters are given in Table S1, ESI. $\dagger$

details hereinafter. For thick layers deposited all at once (CL method), the penetration of the rinsing solvent into the film becomes more and more difficult as the number of layers increases, and this results in higher contents of residual monomer and insulating PEG-PPG-PEG within the polymer film. In the CL case, the rinsing is carried out on thinner films and the removal of the insulating molecules is therefore more efficient, resulting in a stacking of cleaned polymer layers. These observations are confirmed by the trend observed for electrical conductivity (Fig. 2b). The SL electrical conductivity remains almost constant in the $1400-1800 \mathrm{~S} \mathrm{~cm}^{-1}$ range with increasing number of layers, whereas it monotonically declines with increasing number of layers for CL (from almost $1900 \mathrm{~S} \mathrm{~cm}^{-1}$ for 2 layers down to $450 \mathrm{~S} \mathrm{~cm}^{-1}$ for 8 layers). Simultaneously, sheet resistances for the same number of layers are slightly higher for continuous layers compared to stacked ones.

Thick films post-treatment. Since the composition of the films has a strong impact on the polymer packing, we evaluated the influence of the rinsing solvent on the properties of the polymer films. Indeed, the rinsing step contributes to the improvement of the conducting properties of the films through the removal of residual electrically insulating PEG-PPG-PEG,
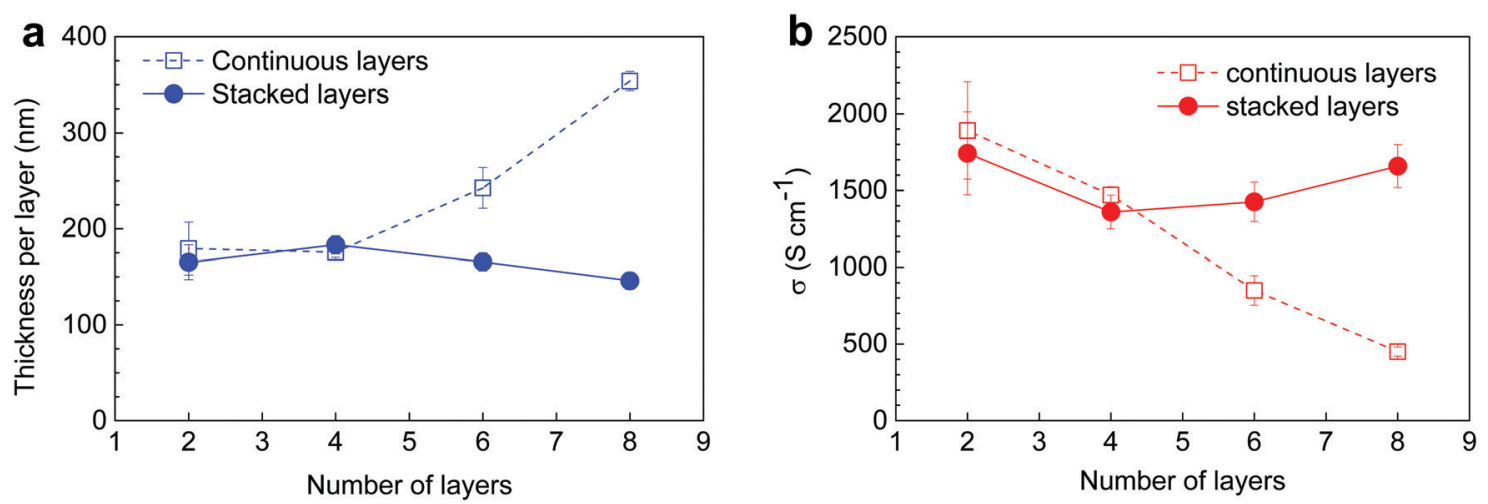

Fig. 2 (a) Evolution of the thickness per layer and (b) electrical conductivity as a function of the number of layers for PEDOT:OTf films polymerized with 5 wt\% NMP, for continuous layers (empty squares) or stacked layers (full rounds). 

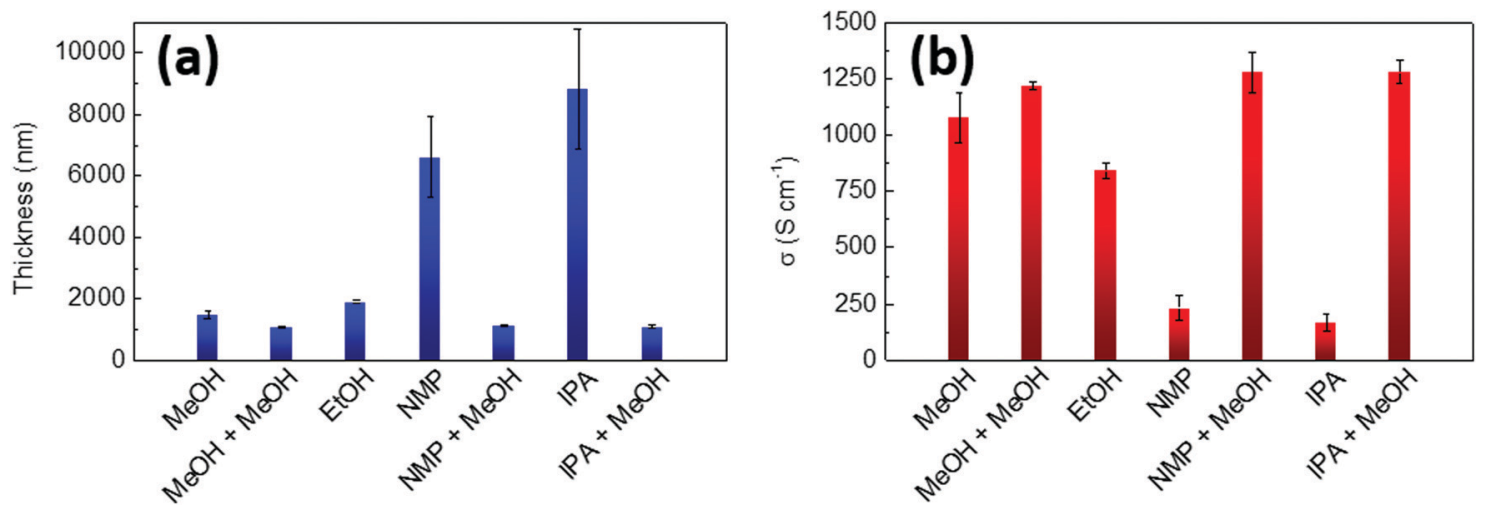

Fig. 3 (a) Thickness and (b) electrical conductivity for PEDOT:OTf samples (8 continuous layers) post-treated with different solvents (methanol, ethanol, $\mathrm{N}$-methylpyrrolidone).

unreacted $\mathrm{Fe}$ (III) salts and free EDOT. Therefore, it may be expected that better solvents for PEG-PPG-PEG would reduce the film thickness and increase the electrical conductivity. PEDOT:OTf films with 2 and 8 layers were prepared using 5 wt\% of NMP in the oxidizing solution. A pre-rinsing step was performed before the final rinsing in ethanol, using solvents having different abilities to solubilize PEG-PPG-PEG, namely methanol $(\mathrm{MeOH})$, ethanol (EtOH) and $N$-methylpyrrolidone (NMP). After spray deposition and thermal annealing, the samples were immersed in the posttreatment solvent for $2 \mathrm{~min}$, and then rinsed in ethanol to remove residues. The obtained films were dried at $70{ }^{\circ} \mathrm{C}$ on a hot plate for $10 \mathrm{~min}$. Fig. 3 shows the impact of the nature of the pre-rinsing solvent on the electrical conductivity properties.

For the thinner series (2 layers) the choice of solvent has little impact on the overall sheet resistance of samples, which lays between 20.8 and $23.5 \Omega \square^{-1}$, but it has already a slight influence on thicknesses which vary between 260 and $350 \mathrm{~nm}$. For thin films, the removal of insulating impurities and unreacted precursors was quite efficient in all cases because a deep penetration of the rinsing solvent is not required. For the thicker series (8 layers, Fig. 3 and Fig. S4, ESI $\dagger$ ), MeOH appears to be the best solvent in order to remove PEG-PPG-PEG and other impurities from the PEDOT:OTf films. A second post-treatment was carried out with this solvent on the films originally rinsed in $\mathrm{MeOH}$, NMP and IPA. It consisted of further rinsing the samples in $\mathrm{MeOH}$ then drying them at $120{ }^{\circ} \mathrm{C}$ during $10 \mathrm{~min}$. The results evidenced a decrease and a homogenization of both sheet resistances and thicknesses for all post-treated samples. Electrical conductivity $\left(1258 \pm 34 \mathrm{~S} \mathrm{~cm}^{-1}\right)$ and Seebeck coefficient were also greatly improved, supporting the hypothesis that the post-treatment with $\mathrm{MeOH}$ is an efficient method to remove insulating impurities from the films. The Seebeck coefficient of the post-treated samples was also increased and reached more common values for naturally doped PEDOT, ${ }^{42}$ between 17 and $20 \mu \mathrm{V} \mathrm{K}{ }^{-1}$. Similar improvement of the Seebeck coefficient by long-time washing ( $>1 \mathrm{~h}$ ) in methanol has been reported in 2017 by Y. Hyeok Lee et $a .^{43}$ for in situ polymerized PEDOT:OTs. This enhancement was explained by the removing of tosylate anions. Here, the post-treatments in methanol were shorter but this dedoping effect could be at the origin of the slight improvement of the Seebeck coefficient.

\section{Structural properties}

Fig. 4 shows GIWAXS diffractograms of three spray-coated PEDOT:OTf films. One thin film was made of two continuous layers, and two other thick sample of eight layers were prepared
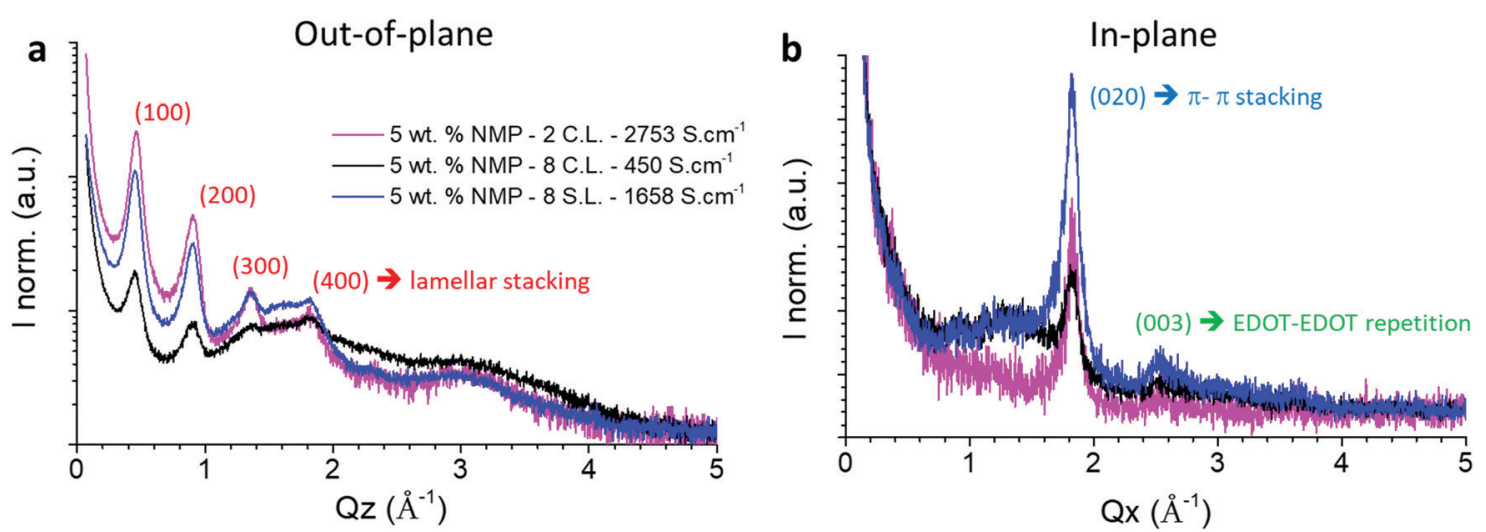

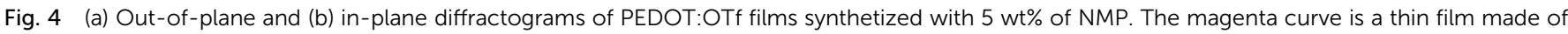

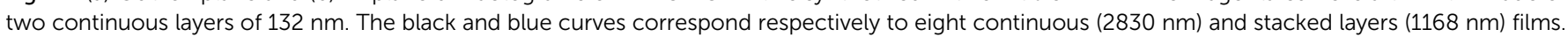
The crystallographic assignments in the out-of-plane and in-plane correspond to an orthorhombic lattice. ${ }^{44}$ 
using the two coating methods presented before. In situ polymerized PEDOT films are known to have a highly anisotropic ordering, namely an edge-on orientation. ${ }^{36,44}$ This is confirmed by the out-of-plane and in-plane measurements shown in Fig. 4 which evidence diffraction peaks characteristic of the PEDOT chains lamellar $\left(Q=0.46,0.92 \AA^{-1}\right)$ and $\pi-\pi\left(Q=1.84 \AA^{-1}\right)$ stacking respectively. The peak observed at $2.52 \AA^{-1}$ (which corresponds to an inter-reticular distance $d=2.49 \AA$ ) in the in-plane diffractograms can tentatively be ascribed to the third order of EDOT-EDOT distance, the first order being estimated at $7.8 \AA$ by Aasmundtveit and Inagäs. ${ }^{44}$

In the out-of-plane diffractograms, for the $2 \mathrm{CL}$ film the diffraction peaks associated to the lamellar stacking can be observed until the fourth order. However, for the three samples only the first two order peaks can be reliably fitted due to the presence of an amorphous phase contribution between 1 and $4 \AA^{-1}$. The full widths at half maximum (FWHM) of the first and second order peaks associated to the lamellar stacking are presented in Table S2 (ESI $\dagger$ ). Qualitatively it appears that while the $2 \mathrm{CL}$ and $8 \mathrm{SL}$ samples give similar results, the $8 \mathrm{CL}$ film evidences poorer crystalline quality in terms of crystallite size and/or lattice distortion. These two parameters, namely the crystallite size $L$ and the lattice distorsion $\varepsilon=\frac{4\langle d-\bar{d}\rangle}{\bar{d}}$, can be determined by a Williamson-Hall type analysis. ${ }^{45}$ Since only two orders of diffraction can be used, the precision of the results is limited. However they indicate a clear trend with values for the crystallite size varying from $11 \pm 2 \mathrm{~nm}$ to $8.5 \pm 2 \mathrm{~nm}$ and $6 \pm 2 \mathrm{~nm}$ for the $2 \mathrm{CL}, 8 \mathrm{SL}$ and $8 \mathrm{CL}$ films respectively. The distortion is of the order of $0.1 \%$ for the three samples. Thus, while increasing the film thickness seems to induce a reduction of the crystallite size in the lamellar stacking direction, the main effect concerns the coating methods with a clearly poorer crystalline quality for the $8 \mathrm{CL}$ film. At the sight of both the out-of-plane and in-plane diffractograms its crystallinity, which qualitatively represents the proportion of crystalline phase with respect to the amorphous component, is the weakest. To be more quantitative, in the in-plane diffractograms measured with the two 8 layers samples the crystalline $\pi-\pi$ stacking peak and the broad amorphous peak at $Q \sim 1.3 \AA^{-1}$ were fitted. The value of the ratio of the areas of the two peaks (crystalline vs. amorphous) is close to 1 for the $8 \mathrm{SL}$ film, and reduces to 0.5 for the 8 CL sample.

\section{Transport properties}

Transport properties of PEDOT:OTf films were studied through electronic conductivity measurements from room temperature down to $3 \mathrm{~K}$. We studied five thin films, prepared with various amounts of NMP in the oxidizing solution. An heterogeneous model based on the works of Kaiser and others ${ }^{28,46,47}$ was used to describe highly conducting polymers with crystallite grains isolated in an amorphous matrix. A quasi-1D metal conduction mechanism was used to describe the electrical conduction within the crystallite (first term of eqn (2)) together with a 3D variable range hopping ( $\mathrm{VRH}$, second term of eqn (2)) and a disordered metal contribution (DM, third term of eqn (2)) associated in parallel in the amorphous parts of the material. A similar model has already been applied for polyaniline (PANI) fibres ${ }^{46}$ but without the disordered metal contribution. This last mechanism $\left(\sigma_{\mathrm{DM}}\right)$ is often considered as a constant compared to other contributions. However, the electron-electron interaction term has to be taken into consideration to properly fit experimental data (eqn (3)). According to the model used in this study, the resistivity is described as follows:

$$
\begin{aligned}
\sigma(T)^{-1} & =\rho(T)=\rho_{\text {crystallites }}+\rho_{\text {amorphous }} \\
& =\rho_{\text {crystallites }}+\left(\sigma_{\mathrm{VRH}}+\sigma_{\mathrm{DM}}\right)^{-1} \\
& =\rho_{\mathrm{m}} \exp \left(-\frac{T_{\mathrm{m}}}{T}\right)+\left(\sigma_{0} \exp \left(-\left(\frac{T_{0}}{T}\right)^{\frac{1}{1+d}}\right)+\sigma_{\mathrm{DM}}(T)\right)^{-1}
\end{aligned}
$$

$$
\sigma_{\mathrm{DM}}(T)=\sigma_{0 \mathrm{DM}}+m T^{\frac{1}{2}}
$$

where $\rho_{\mathrm{m}}$ and $\sigma_{0}$ are pre-factors of the quasi-1D metal and VRH conduction respectively. $T_{\mathrm{m}}$ is the temperature above which phonons can backscatter charge carriers in this highly anisotropic metallic conduction, and $T_{0}$ is the hopping activation energy. The $d$ exponent corresponds to the dimensionality of the transport in the frame of the VRH, i.e. $d=1,2$ or 3 if the hopping takes place within states in $1 \mathrm{D}$ (e.g. along polymer chains), $2 \mathrm{D}$ or $3 \mathrm{D}$ (volume) respectively. $\sigma_{0 \mathrm{D} m}$ is a constant and $m$ is a prefactor linked to the electron-electron interactions.

The transport properties of the five measured samples are presented in Table 1 and Fig. S5 (ESI $\dagger$ ) curves and fitting parameters are shown in Fig. S6a and Table S3 (ESI $\dagger$ ). The electrical conductivity at room temperature $(\sigma(300 \mathrm{~K}))$ increases until $5 \mathrm{wt} \%$ of NMP content for PEDOT:OTf thin films. It is worth noting that for these samples the resistivity ratio $\rho_{\mathrm{r}}=\rho(3 \mathrm{~K}) / \rho(300 \mathrm{~K})$ decreases with the NMP content, which is indicative of a lower structural disorder inside the films. ${ }^{48}$ The film with $6 \mathrm{wt} \%$ NMP has a much lower room temperature electrical conductivity and a higher resistivity ratio $\left(\rho_{\mathrm{r}}=5\right)$. In order to understand further the origin of this behaviour, we used the reduced activation

Table 1 Summary of transport property values at $300 \mathrm{~K}$ of spray-coated

\begin{tabular}{|c|c|c|c|c|c|c|}
\hline \multicolumn{3}{|c|}{ General properties } & \multirow{2}{*}{$\frac{\begin{array}{l}\text { Resistivity } \\
\text { ratio }\end{array}}{\frac{\rho(3 \mathrm{~K})}{\rho(300 \mathrm{~K})}}$} & \multirow{2}{*}{$\begin{array}{l}\text { Quasi 1D-metal } \\
\text { contribution } \\
\frac{\rho_{1 \mathrm{D}-m}{ }^{a}}{\rho(300 \mathrm{~K})} \\
(\%)\end{array}$} & \multicolumn{2}{|c|}{$\begin{array}{l}\text { Amorphous phase } \\
\text { contribution }\end{array}$} \\
\hline $\begin{array}{l}\text { NMP } \\
\text { (wt } \%)\end{array}$ & $\begin{array}{l}\text { \#CL } \\
(-)\end{array}$ & $\begin{array}{l}\sigma(300 \mathrm{~K}) \\
\left(\mathrm{S} \mathrm{cm}^{-1}\right)\end{array}$ & & & $\begin{array}{l}\frac{\sigma_{\mathrm{VRH} 3 \mathrm{D}} a}{\sigma_{\mathrm{amorphe}}} \\
(\%)\end{array}$ & $\begin{array}{l}\frac{\sigma_{\mathrm{DM}}}{\sigma_{\text {amorphe }}}{ }^{(\%)} \\
(\%)\end{array}$ \\
\hline 0 & 2 & 400 & 2.04 & 5.8 & 47.4 & 52.4 \\
\hline 4 & 2 & 1477 & 1.72 & 5.5 & 55.6 & 44.4 \\
\hline 5 & 2 & 2562 & 1.59 & 4.9 & 64.6 & 35.4 \\
\hline 6 & 2 & 348 & 5.00 & 5.0 & 53.0 & 47.0 \\
\hline 5 & 8 & 527 & 2.32 & 8.3 & 30.7 & 69.3 \\
\hline
\end{tabular}
PEDOT:OTf films with increasing quantity of NMP. All films were deposited using a continuous coating method $(\mathrm{CL})$. The $8-\mathrm{CL}$ film $(2.03 \pm 0.04 \mu \mathrm{m})$ contains trapped PEG-PPG-PEG after the rinsing step (no post-treatment)

${ }^{a}$ Ratio calculated for $T=300 \mathrm{~K}$. 


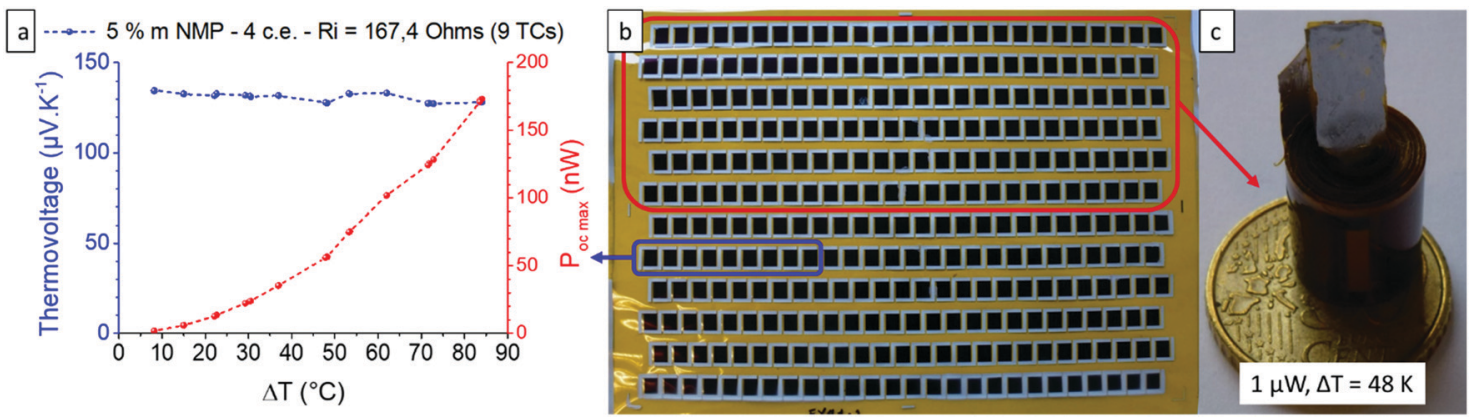

Fig. 5 (a) Thermovoltage and power density measured for a 9-thermocouples TEG module (b) picture of 312 spray-coated legs on a $25 \mu \mathrm{m}$ thick polyimide foil (c) 3D TEG composed of 156 linked and rolled thermocouples $\left(R_{\mathrm{i}}=2.9 \mathrm{k} \Omega\right)$

energy defined as $W=\frac{\partial \ln (\sigma)}{\partial \ln (T)}$ (Fig. S6b, ESI $\dagger$ ). The curves plotting $W$ as a function of $\ln (T)$ show a positive slope at low temperatures except for the thin film synthetized with $6 \mathrm{wt} \%$ of NMP. A positive slope indicates that PEDOT:OTf is on the metallic side of the metal-semiconductor transition. ${ }^{47}$ The film with $6 \mathrm{wt} \%$ of NMP is on the insulating side of the M-I transition, as shown by the $W(\ln T)$ negative slope, due to the increase of disorder within the film.

The ratio of quasi 1D-metal resistivity on the overall resistivity at room temperature indicates that parts where quasi 1D-metal transport occurs (high conductivity) represent only 4.9 to $8.3 \%$ of the total resistivity at $300 \mathrm{~K}$. Thus the main limiting contributions to PEDOT:OTf conductivity come from the amorphous phase, i.e. disordered metal and 3D VRH transport regimes in parallel. For thin films, as $\sigma(300 \mathrm{~K})$ rises, both VRH and DM conductivities rise in magnitude. However, the VRH contribution becomes dominant in the amorphous part and represents almost $65 \%$ of the $\sigma_{\text {amorphous }}$ for the thin films synthesized with $5 \mathrm{wt} \%$ of NMP. Values reported in Table 1 and Table S3 (ESI $\dagger$ ) show that the electrical conductivity in the thick $8 \mathrm{CL}$ film is mainly supported by degraded quasi 1D-metal and disordered metal like conductions. This degradation for both semiconducting and metallic conduction mechanisms may be linked to the excess of trapped PEG-PPG-PEG in thick amorphous samples as suggested by the previous GIWAXS diffractograms and by the $\rho_{\mathrm{r}}$ value of 2.3 (higher disorder).

\section{Fabrication of spray-coated TEG}

After optimizing the solution formulation and the spray coating deposition parameters, the production of a printed TEG was carried out using the optimized oxidative solution formulation (i.e. containing $5 \mathrm{wt} \% \mathrm{NMP}$ and $63 \mathrm{~g} \mathrm{~L}^{-1} \mathrm{Fe}(\mathrm{OTf})_{3}$ ) and the stacked layers protocol. The TEG was composed of 156 spraycoated PEDOT:OTf and silver thermocouples (TCs), which corresponds to 312 legs in total as illustrated in Fig. 5a. First, PEDOT:OTf legs were printed on a flexible $25 \mu \mathrm{m}$ thick polyimide foil. Four stacked layers were used, so that the PEDOT:OTf legs had a mean thickness of $650 \pm 40 \mathrm{~nm}$. Then, silver legs were spray-coated on top. Full lines of two-dimensional (2D) TCs were chopped off physically and electrically linked end to end to form a $189 \mathrm{~cm}$ long stripe (Fig. S7, ESI $\dagger$ ). This 2D TEG strip was then rolled and sealed with polyimide tape to form a $3 \mathrm{D}$ TEG. ${ }^{49-51}$

In order to estimate the power density per printed surface (in $\mathrm{nW} \mathrm{K} \mathrm{K}^{-2} \mathrm{~m}^{-2}$ ) of this rolled 2D TEG, nine TCs were cut and analyzed with a thermoelectric power measurement test bench (Fig. S8, ESI $\dagger$ ). This characterization test bench allowed us to measure the open-circuit voltage and to extract the Seebeck coefficient per thermocouple in order to estimate the thermoelectric power density. Each thermocouple has a Seebeck coefficient of about $14.6 \mu \mathrm{V} \mathrm{K}^{-1}$ which is less than the pristine PEDOT:OTf because of the positive Seebeck coefficient of silver ink (measured at $2.31 \pm 0.2 \mu \mathrm{V} \mathrm{K}^{-1}$ ). The theoretical maximum electrical power output of the nine TCs was calculated with the open-circuit voltage $\left(V_{\mathrm{OC}}\right)$ and internal resistance $\left(R_{\mathrm{i}}\right)$ through the relation $P_{\mathrm{OC}}=\frac{V_{\mathrm{OC}}^{2}}{4 R_{\mathrm{i}}}$. The maximum power output is obtained if the TEG is linked with a load of the same resistance, here 167.4 $\Omega$. Each thermocouple has a mean printed surface of $1.68 \pm 0.08 \mathrm{~cm}^{2}$. Power density for this particular TEG was calculated to be $16.5 \pm 0.5 \mathrm{nW} \mathrm{K} \mathrm{K}^{-2}$. Hence $1 \mu \mathrm{W}$ can be harvested when the TEG is subjected to a $48.1 \mathrm{~K}$ thermal gradient, which is in the same order of magnitude than PEDOT:PSS screen printed module reported by Wei et al. ${ }^{52}$ Further developments and in particular replacing silver ink by a n-type material like $\mathrm{Ni}$, constantan or poly(nickel 1,1,2,2ethenetetrathiolate) or n-type organic materials ${ }^{8,13,14,53}$ would certainly lead to significant improvement.

\section{Conclusion}

In this work, we demonstrate that ultra-sonic spray coating offers a precious tool to create large surface and thick films of in situ polymerized PEDOT based material on different substrates (glass, polyimide). PEDOT:OTf appears as a material of choice since high electrical conductivity were achieved, in particular for thick films, after fine control of the process parameters. Structural characterizations of the material were performed, pointing out significant alterations when different protocols were used for the fabrication of sprayed PEDOT:OTf films. Electrical conductivity measurements down to $3 \mathrm{~K}$ also exhibit different values with respect to the different fabrication protocols, and a model was proposed for explaining the conduction 
mechanisms at stake in these films. From this model, we understood that the electronic transport is mainly limited by the amorphous domains, and, as a result, efforts have to focus on this part in order to improve the device performances. Eventually, a proof of concept was realized through the fabrication of a printed TEG. Though performances appear rather moderate $\left(16.5 \pm 0.5 \mathrm{nW} \mathrm{K} \mathrm{K}^{-2}\right)$, there is room for improvement, in particular through use of high performance n-type materials. The use of a spray-coated PEDOT:OTf material with high conductivity appears as a promising alternative for printed organic thermoelectric generators, and possibly for other organic electronics based applications.

\section{Conflicts of interest}

There are no conflicts to declare.

\section{Acknowledgements}

The authors acknowledge the ANR for funding through the project Harvesters (ANR-16-CE05-0029-01).

\section{References}

1 C. Forman, I. K. Muritala, R. Pardemann and B. Meyer, Estimating the global waste heat potential, Renewable Sustainable Energy Rev., 2016, 57, 1568-1579, DOI: 10.1016/ j.rser.2015.12.192.

2 G.-H. Kim, L. Shao, K. Zhang and K. P. Pipe, Engineered doping of organic semiconductors for enhanced thermoelectric efficiency, Nat. Mater., 2013, 12, 719.

3 L. E. Bell, Cooling, Heating, Generating Power, and Recovering Waste Heat with Thermoelectric Systems, Science, 2008, 321, 1457-1461, DOI: 10.1126/science.1158899.

4 H. Edwards, Q. Niu and A. de Lozanne, Thermoelectric Conversion, in Wiley Encycl. Electr. Electron. Eng., ed. J. G. Webster, John Wiley \& Sons, Inc., Hoboken, NJ, USA, 1999, DOI: 10.1002/047134608X.W3044.

5 O. Bubnova and X. Crispin, Towards polymer-based organic thermoelectric generators, Energy Environ. Sci., 2012, 5, 9345, DOI: 10.1039/c2ee22777k.

6 M. Haras and T. Skotnicki, Thermoelectricity for IoT - A review, Nano Energy, 2018, 54, 461-476, DOI: 10.1016/ j.nanoen.2018.10.013.

7 B. Poudel, Q. Hao, Y. Ma, Y. Lan, A. Minnich, B. Yu, X. Yan, D. Wang, A. Muto, D. Vashaee, X. Chen, J. Liu, M. S. Dresselhaus, G. Chen and Z. Ren, High-Thermoelectric Performance of Nanostructured Bismuth Antimony Telluride Bulk Alloys, Science, 2008, 320, 634-638, DOI: 10.1126/ science.1156446.

8 Q. Zhang, Y. Sun, W. Xu and D. Zhu, Organic Thermoelectric Materials: Emerging Green Energy Materials Converting Heat to Electricity Directly and Efficiently, Adv. Mater., 2014, 26, 6829-6851, DOI: 10.1002/adma.201305371.
9 Y. Li, Y. Du, Y. Dou, K. Cai and J. Xu, PEDOT-based thermoelectric nanocomposites - A mini-review, Synth. Met., 2017, 226, 119-128, DOI: 10.1016/j.synthmet.2017.02.007.

10 M. Bharti, A. Singh, S. Samanta and D. K. Aswal, Conductive polymers for thermoelectric power generation, Prog. Mater. Sci., 2018, 93, 270-310, DOI: 10.1016/j.pmatsci.2017.09.004.

11 J. F. Ponder, A. K. Menon, R. R. Dasari, S. L. Pittelli, K. J. Thorley, S. K. Yee, S. R. Marder and J. R. Reynolds, Conductive, Solution-Processed Dioxythiophene Copolymers for Thermoelectric and Transparent Electrode Applications, Adv. Energy Mater., 2019, 9, 1900395, DOI: 10.1002/ aenm.201900395.

12 C.-J. Yao, H.-L. Zhang and Q. Zhang, Recent Progress in Thermoelectric Materials Based on Conjugated Polymers, Polymers, 2019, 11, 107, DOI: 10.3390/polym11010107.

13 D. Huang, H. Yao, Y. Cui, Y. Zou, F. Zhang, C. Wang, H. Shen, W. Jin, J. Zhu, Y. Diao, W. Xu, C. Di and D. Zhu, ConjugatedBackbone Effect of Organic Small Molecules for n-Type Thermoelectric Materials with ZT over 0.2, J. Am. Chem. Soc., 2017, 139, 13013-13023, DOI: 10.1021/jacs.7b05344.

14 O. Bardagot, P. Kubik, T. Marszalek, P. Veyre, A. A. Medjahed, M. Sandroni, B. Grévin, S. Pouget, T. N. Domschke, A. Carella, S. Gambarelli, W. Pisula and R. Demadrille, Impact of Morphology on Charge Carrier Transport and Thermoelectric Properties of N-Type FBDOPV-Based Polymers, Adv. Funct. Mater., 2020, 2000449, DOI: 10.1002/adfm.202000449.

15 R. R. Søndergaard, M. Hösel and F. C. Krebs, Roll-to-Roll fabrication of large area functional organic materials, J. Polym. Sci., Part B: Polym. Phys., 2013, 51, 16-34, DOI: 10.1002/polb.23192.

16 C. T. Hong, Y. H. Kang, J. Ryu, S. Y. Cho and K.-S. Jang, Spray-printed CNT/P3HT organic thermoelectric films and power generators, J. Mater. Chem. A, 2015, 3, 21428-21433, DOI: $10.1039 /$ C5TA06096F.

17 R. R. Søndergaard, M. Hösel, N. Espinosa, M. Jørgensen and F. C. Krebs, Practical evaluation of organic polymer thermoelectrics by large-area R2R processing on flexible substrates, Energy Sci. Eng., 2013, 1, 81-88, DOI: 10.1002/ese3.8.

18 B. C. Sales, Electron Crystals and Phonon Glasses: A New Path to Improved Thermoelectric Materials, MRS Bull., 1998, 23, 15-21, DOI: 10.1557/S0883769400031419.

19 O. Bubnova, Z. U. Khan, A. Malti, S. Braun, M. Fahlman, M. Berggren and X. Crispin, Optimization of the thermoelectric figure of merit in the conducting polymer poly(3,4ethylenedioxythiophene), Nat. Mater., 2011, 10, 429-433, DOI: $10.1038 /$ nmat3012.

20 Q. Yao, L. Chen, W. Zhang, S. Liufu and X. Chen, Enhanced thermoelectric performance of single-walled carbon nanotubes/polyaniline hybrid nanocomposites, ACS Nano, 2010, 4, 2445-2451, DOI: 10.1021/nn1002562.

21 Q. Wang, Q. Yao, J. Chang and L. Chen, Enhanced thermoelectric properties of CNT/PANI composite nanofibers by highly orienting the arrangement of polymer chains, J. Mater. Chem., 2012, 22, 17612, DOI: 10.1039/c2jm32750c.

22 L. Horta-Romarís, M. V. González-Rodríguez, A. Lasagabáster, F. Rivadulla and M.-J. Abad, Thermoelectric properties and 
intrinsic conduction processes in DBSA and NaSIPA doped polyanilines, Synth. Met., 2018, 243, 44-50, DOI: 10.1016/ j.synthmet.2018.06.002.

23 I. Petsagkourakis, E. Pavlopoulou, G. Portale, B. A. Kuropatwa, S. Dilhaire, G. Fleury and G. Hadziioannou, Structurally-driven Enhancement of Thermoelectric Properties within Poly(3,4-ethylenedioxythiophene) thin Films, Sci. Rep., 2016, 6, 30501, DOI: 10.1038/srep30501.

24 Y. Lu, J.-Y. Wang and J. Pei, Strategies To Enhance the Conductivity of n-Type Polymer Thermoelectric Materials, Chem. Mater., 2019, 31, 6412-6423, DOI: 10.1021/ acs.chemmater.9b01422.

25 P. Hojati-Talemi, C. Bächler, M. Fabretto, P. Murphy and D. Evans, Ultrathin Polymer Films for Transparent Electrode Applications Prepared by Controlled Nucleation, ACS Appl. Mater. Interfaces, 2013, 5, 11654-11660, DOI: 10.1021/ am403135p.

26 M. N. Gueye, A. Carella, R. Demadrille and J. P. Simonato, AllPolymeric Flexible Transparent Heaters, ACS Appl. Mater. Interfaces, 2017, 9, 27250-27256, DOI: 10.1021/acsami.7b08578.

27 D. T. Papanastasiou, A. Schultheiss, D. Muñoz-Rojas, C. Celle, A. Carella, J.-P. Simonato and D. Bellet, Transparent Heaters: A Review, Adv. Funct. Mater., 2020, 1910225, DOI: $10.1002 /$ adfm.201910225.

28 M. N. Gueye, A. Carella, J. Faure-Vincent, R. Demadrille and J.-P. Simonato, Progress in understanding structure and transport properties of PEDOT-based materials: a critical review, Prog. Mater. Sci., 2020, 108, 100616, DOI: 10.1016/ j.pmatsci.2019.100616.

29 S.-M. Kim, C.-H. Kim, Y. Kim, N. Kim, W.-J. Lee, E.-H. Lee, D. Kim, S. Park, K. Lee, J. Rivnay and M.-H. Yoon, Influence of PEDOT:PSS crystallinity and composition on electrochemical transistor performance and long-term stability, Nat. Commun., 2018, 9, 3858, DOI: 10.1038/s41467-018-06084-6.

30 B. Bessaire, M. Mathieu, V. Salles, T. Yeghoyan, C. Celle, J.-P. Simonato and A. Brioude, Synthesis of Continuous Conductive PEDOT:PSS Nanofibers by Electrospinning: A Conformal Coating for Optoelectronics, ACS Appl. Mater. Interfaces, 2017, 9, 950-957, DOI: 10.1021/acsami.6b13453.

31 F. Jonas, G. Heywang, W. Schmidtberg, J. Heinze and M. Dietrich, Polythiophenes, process for their preparation and their use, US4959430A, 1989.

32 K. Zuber, M. Fabretto, C. Hall and P. Murphy, Improved PEDOT Conductivity via Suppression of Crystallite Formation in Fe(III) Tosylate During Vapor Phase Polymerization, Macromol. Rapid Commun., 2008, 29, 1503-1508, DOI: 10.1002/marc.200800325.

33 M. Fabretto, M. Müller, K. Zuber and P. Murphy, Influence of PEG-ran-PPG Surfactant on Vapour Phase Polymerised PEDOT Thin Films, Macromol. Rapid Commun., 2009, 30, 1846-1851, DOI: 10.1002/marc.200900371.

34 M. Mueller, M. Fabretto, D. Evans, P. Hojati-Talemi, C. Gruber and P. Murphy, Vacuum vapour phase polymerization of high conductivity PEDOT: Role of PEG-PPG-PEG, the origin of water, and choice of oxidant, Polymer, 2012, 53, 2146-2151, DOI: 10.1016/j.polymer.2012.03.028.
35 N. Massonnet, A. Carella, A. de Geyer, J. Faure-Vincent and J.-P. Simonato, Metallic behaviour of acid doped highly conductive polymers, Chem. Sci., 2015, 6, 412-417, DOI: 10.1039/C4SC02463J.

36 M. N. Gueye, A. Carella, N. Massonnet, E. Yvenou, S. Brenet, J. Faure-Vincent, S. Pouget, F. Rieutord, H. Okuno, A. Benayad, R. Demadrille and J.-P. Simonato, Structure and Dopant Engineering in PEDOT Thin Films: Practical Tools for a Dramatic Conductivity Enhancement, Chem. Mater., 2016, 28, 3462-3468, DOI: 10.1021/acs.chemmater.6b01035.

37 S. van Reenen and M. Kemerink, Correcting for contact geometry in Seebeck coefficient measurements of thin film devices, Org. Electron., 2014, 15, 2250-2255, DOI: 10.1016/ j.orgel.2014.06.018.

38 Y.-H. Ha, N. Nikolov, S. K. Pollack, J. Mastrangelo, B. D. Martin and R. Shashidhar, Towards a Transparent, Highly Conductive Poly(3,4-ethylenedioxythiophene), Adv. Funct. Mater., 2004, 14, 615-622, DOI: 10.1002/adfm.200305059.

39 T. Park, C. Park, B. Kim, H. Shin and E. Kim, Flexible PEDOT electrodes with large thermoelectric power factors to generate electricity by the touch of fingertips, Energy Environ. Sci., 2013, 6, 788, DOI: 10.1039/c3ee23729j.

40 L. Tzounis, Organic Thermoelectrics and Thermoelectric Generators (TEGs), Adv. Thermoelectr. Mater. Energy Harvest. Appl., 2019, DOI: 10.5772/intechopen.86946.

41 Z. Fan and J. Ouyang, Thermoelectric Properties of PEDOT:PSS, Adv. Electron. Mater., 2019, 5, 1800769, DOI: 10.1002/ aelm.201800769.

42 J. Luo, D. Billep, T. Waechtler, T. Otto, M. Toader, O. Gordan, E. Sheremet, J. Martin, M. Hietschold, D. R. T. Zahn and T. Gessner, Enhancement of the thermoelectric properties of PEDOT:PSS thin films by post-treatment, J. Mater. Chem. A, 2013, 1, 7576, DOI: 10.1039/c3ta11209h.

43 Y. H. Lee, J. Oh, S.-S. Lee, H. Kim and J. G. Son, Highly Ordered Nanoconfinement Effect from EvaporationInduced Self-Assembly of Block Copolymers on In Situ Polymerized PEDOT:Tos, ACS Macro Lett., 2017, 6, 386-392, DOI: 10.1021/acsmacrolett.7b00137.

44 K. E. Aasmundtveit, E. J. Samuelsen, L. A. A. Pettersson, O. Inganäs, T. Johansson and R. Feidenhans'l, Structure of thin films of poly(3,4-ethylenedioxythiophene), Synth. Met., 1999, 101, 561-564, DOI: 10.1016/S0379-6779(98)00315-4.

45 J. Rivnay, S. C. B. Mannsfeld, C. E. Miller, A. Salleo and M. F. Toney, Quantitative Determination of Organic Semiconductor Microstructure from the Molecular to Device Scale, Chem. Rev., 2012, 112, 5488-5519, DOI: 10.1021/ cr3001109.

46 A. B. Kaiser, Systematic Conductivity Behavior in Conducting Polymers: Effects of Heterogeneous Disorder, Adv. Mater., 2001, 13, 927-941, DOI: 10.1002/1521-4095(200107)13:12/ $13<927$ ::AID-ADMA927> 3.0.CO;2-B.

47 A. B. Kaiser, Electronic transport properties of conducting polymers and carbon nanotubes, Rep. Prog. Phys., 2001, 64, 1-49.

48 Handbook of conducting polymers, ed. T. A. Skotheim, R. L. Elsenbaumer and J. R. Reynolds, M. Dekker, New York, 2nd edn, rev. and expanded, 1998. 
49 J. Weber, K. Potje-Kamloth, F. Haase, P. Detemple, F. Völklein and T. Doll, Coin-size coiled-up polymer foil thermoelectric power generator for wearable electronics, Sens. Actuators, A, 2006, 132, 325-330, DOI: 10.1016/ j.sna.2006.04.054.

50 A. Chen, D. Madan, P. K. Wright and J. W. Evans, Dispenserprinted planar thick-film thermoelectric energy generators, J. Micromech. Microeng., 2011, 21, 104006, DOI: 10.1088/ 0960-1317/21/10/104006.

51 H. Fang, B. C. Popere, E. M. Thomas, C.-K. Mai, W. B. Chang, G. C. Bazan, M. L. Chabinyc and R. A. Segalman,
Large-scale integration of flexible materials into rolled and corrugated thermoelectric modules, J. Appl. Polym. Sci., 2017, 44208, DOI: 10.1002/app.44208.

52 Q. Wei, M. Mukaida, K. Kirihara, Y. Naitoh and T. Ishida, Polymer thermoelectric modules screen-printed on paper, RSC Adv., 2014, 4, 28802-28806, DOI: 10.1039/C4RA04946B.

53 K. Shi, F. Zhang, C. A. Di, T. W. Yan, Y. Zou, X. Zhou, D. Zhu, J. Y. Wang and J. Pei, Toward High Performance n-Type Thermoelectric Materials by Rational Modification of BDPPV Backbones, J. Am. Chem. Soc., 2015, 137, 6979-6982, DOI: $10.1021 /$ jacs.5b00945. 